\title{
Release of Myofascial Pain with Deep Cross-Friction Named "Roptrotherapy"
}

Andre Farasyn, PhD, PT, DO

Faculty of Physical Education and Rehabilitation Sciences, Vrije Universiteit Brussel, Brussels, Belgium

Purpose: To introduce a new myofascial release method named "roptrotherapy" that consists of deep cross-friction massage with the aid of a myofascial $\mathrm{T}$ bar (roptron).

Description: The intervention of roptrotherapy consists of a 30-minute session, total, of deep-friction massage with the aid of a myofascial $\mathrm{T}$ bar. These bars are made of bronze, a neutral material to skin. The advantages of bronze over wooden or plastic fabrication is that the resulting pressure bars are easier to use by hand and contribute to the compression force by their weight $(0.8 \mathrm{~kg})$, resulting in less fatigue for the therapist. The work is performed by the therapist within the threshold of tolerable pain, applying a compressive force of $5-10 \mathrm{~kg} / \mathrm{cm}^{2}$ on each of the myofascial trigger points found.

Treatment by means of roptrotherapy aims mainly

- to treat the myofibroses present in skeletal muscles and to reduce indirectly the enthesopathic pain at the level of an articulation (better know as a "tendinosis," which is not the same as a "tendinitis").

- to reduce compartmental muscle compression (slight edema present in the muscle).

- to release the neuro-entrapment of sensory afferent peripheral sensitive nerves (explained in the "barrier-dam" hypothesis $\left.{ }^{(1)}\right)$.

Relationship to Fascia: In cases of acute musculoskeletal pain, the compartmental pressure in the muscles increases pathophysiologically as a result of muscle soreness: an interstitial edema arises as a result of local muscle damage. At the same time, connective scar tissue forms ${ }^{(2-4)}$. These myofibroses gradually entrap a number of sensory nerves and contribute to the creation of a referred muscle pain syndrome ${ }^{(1)}$. Regardless of the original cause, chronic

This article is the expanded abstract of a workshop presented at the Second International Fascia Research Congress; October 27 - 30, 2009; Amsterdam, Netherlands. connective tissue fibrosis is detrimental, because it leads to increased tissue stiffness and further movement impairment.

The effect of deep-friction technique, named roptrotherapy, is supposed to be beneficial for general body relaxation and to be able to regenerate connective myofascial scar tissues. Not only is the compartmental compression reduced, but in addition, the entrapment of sensory nerves is released ${ }^{(1)}$. The myofibrotic release by application of deep crossfriction on damaged muscle tissue will augment the natural processes of tissue repair ${ }^{(5,6)}$.

Suggestions for Scientific Research: Further research is needed to explore the therapeutic effect of roptrotherapy on pain rating, disability, and pressure pain thresholds in patients with chronic musculoskeletal syndromes - for example, nonspecific low-back pain, tension headaches, and sports lesions.

Evaluation of new approaches is needed for screening and diagnosis of fasciae, including new technologies, testing strategies, and follow-up protocols for patients with myofascial pain syndromes. A new method of transverse-friction algometry has been already undertaken ${ }^{(7)}$, and a new device with additional software is in development.

Cross-disciplinary Applications: New structures under consideration to further support this kind of work include studies of multidisciplinary teams working on highly integrative research areas and an emphasis on integration across medical and costeffectiveness economic spheres.

KEYWORDS: Myofascial pain, referred pain, pressure pain, cross-friction massage, roptrotherapy

\section{CONFLICT OF INTEREST NOTIFICATION}

The author declares that there are no conflicts of interest.

\section{COPYRIGHT}

Published under the CreativeCommons Attribution-NonCommercial-NoDerivs 3.0 License. 


\section{REFERENCES}

1. Farasyn A. Referred muscle pain is primarily peripheral in origin: the "barrier-dam" theory. Med Hypotheses 2007; 68(1): 144-50.

2. Farasyn A, Meeusen R. Pressure pain thresholds in healthy subjects: influence of physical activity, history of lower back pain and the use of endermology as a placebo-like treatment. J Bodyw Mov Ther 2003; 7(1): 53-61.

3. Farasyn A, Meeusen R. The influence of non-specific low back pain on pressure pain thresholds and disability. Eur J Pain 2005; 9(4): 375-381.

4. Farasyn A, Meeusen R. Validity of the new Backache Index (BAI) in patients with low back pain. Spine $J$ 2006; 6(5): 565-571.

5. Farasyn A, Meeusen R, Nijs J. A pilot randomized placebocontrolled trial of roptro-therapy in patients with subacute low back pain. J Back Musculoskelet Rehabil 2006;19(4): 111-117.
6. Farasyn A, Meeusen R. Effect of roptrotherapy on pressure pain thresholds in patients with non-specific low back pain. $J$ Musculoskelet Pain 2007; 15(1): 41-53.

7. Farasyn AD, Meeusen R, Nijs J. Validity of cross-friction algometry procedure in referred muscle pain syndromes: preliminary results of a new referred pain provocation technique with the aid of a Fischer pressure algometer in patients with nonspecific low back pain. Clin J Pain 2008; 24(5): 456-462.

Corresponding author: Andre Farasyn, Associate Professor Doctor, Faculty of Physical Education and Rehabilitation Sciences, Vrije Universiteit Brussel, Laarbeeklaan 103, Brussels, 1090, Belgium.

E-mail: andre.farasyn@vub.ac.be Website: http://www.roptrotherapy.info 